\title{
A Complete Bibliography of Interpreting and Translation Just One Click Away
}

\author{
Javier Franco Aixelá \\ University of Alicante \\ Javier.Franco@ua.es
}

\begin{abstract}
The article is a brief presentation of the structure, aims and rationale of BITRA (Bibliography of Interpreting and Translation of Alicante). BITRA is an on-line database which already (November, 2001) comprises more than 8,000 documents and which aspires to cover all the literature on interpreting and translation taking advantage of information technology. This database is: (1) International: It accepts works from any country and written in any language, and although English is the lingua franca, there are several working languages (Spanish, Catalan, German, French and English are already used, and Dutch will follow shortly) so that as many users as possible can search in their mother tongues. (2) Annotated: Apart from the mere bibliographic information, there are metatextual fields aimed at offering an abstract, commenting on special traits of the text or reproducing the table of contents. (3) Interactive: There is a system for suggestions and contributions that allows users to propose changes in the existing data or the inclusion of new documents. (4) Flexible: Apart from its interactive possibilities, BITRA allows searches to be performed using any criterion or combination of criteria, from author, language or type of document to the subjects the documents deal with. (5) Open and free: In keeping with its academic nature, BITRA is open to everybody without any sort of subscription or payment.
\end{abstract}

BITRA stands for "Bibliography of Interpreting and Translation of Alicante". To put it simply, it is an international annotated bibliography on translation and interpreting which 
can be freely searched on the Internet (http://www.ua.es/dfing/tra_int/bitra_en.htm) in English, Spanish, French, German and Catalan (soon also in Dutch).

Translation and interpreting studies have undergone an unprecedented boom which has brought about an abundant theoretical and applied production that cannot be ignored. However, the search for relevant bibliography on teaching, research or professional practice often involves an excessive effort and meagre results. Admittedly, at least since 1970 there have been occasional praiseworthy examples of partial bibliographies on translation and, right now, there are one or two journals, like Translation Studies Abstracts, which focus on this area. Nevertheless, the fragmentation and the limited nature of this material make searching difficult and, regrettably, it has to be stated that in the world of translation and interpreting there is no really flexible bibliography, capable of constant growth and open to contributions, available in a single international and user-friendly tool. BITRA tries to meet all these needs, taking advantage of current IT in order to fill this bibliographical gap in our discipline.

If we consider that the scientific study of translation does not appear at least until after the Second World War, and that the dramatic upsurge in publications brought about by modern Translation Studies does not take place until the 80 s, we can call ours a relatively young discipline, so that collecting a very significant portion of the literature on translation and interpreting in a single bibliographical and multilingual tool is at least thinkable. Indeed, the vast potential of the Internet, with all its interactive possibilities, make it perfectly possible, even if laborious.

At present (November, 2001) BITRA comprises more than 8,000 documents including books, chapters, articles, dissertations and journals on translation and interpreting. Though we are aware of the utopian nature of the enterprise, this ever-growing database (it is updated once a month) aspires to encompass in a systematic way everything published on interpreting and translation, by classifying the material in accordance with multiple simultaneous criteria and completing the bibliographical references with metatextual information. In this connection, BITRA has been designed to provide classifications and metatextual comments enabling the researchers, the students or the professionals to find what has been published on any subject and to determine with a reasonable degree of certainty whether a given document will prove helpful.

In line with its academic nature, searching in this database is free and open to all, and the intention is for it to stay this way. However, acknowledgement would obviously be appreciated whenever BITRA proves helpful to its users.

In keeping with its international vocation, BITRA is intended to be as accessible as possible to the greatest number of users by means of an open policy as regards working languages. The progressively universal nature of English has led us to adopt it as the lingua franca in BITRA, but this does not at all mean that it is the only working language used. Generally speaking, the data is offered in the language of each document and also in English, with Spanish acting as an auxiliary language in many cases. However, multilingual reality has been respected whenever the ratio of effort to cost and the necessary transparency have made this possible. To be more specific, all fields which were capable 
of being systematised due to their having a limited number of possibilities (subjects, type and language) are already (or will soon be) offered in all the working languages.

As to sources, BITRA uses practically every conceivable means, from bibliographical references on books, articles or dissertations, to the information publishers issue through the Internet, and including the catalogues of all sort of libraries. There is one exception. In order not to interfere with the work of other colleagues, I have made every effort to avoid taking any reference from publications (books or journals) specifically focused on translation or interpreting bibliography, although it is impossible to guarantee that no reference comes indirectly from these sources. Being a public project and taking into account that the Internet allows free-flowing communication with users, it would be especially helpful to receive contributions from the authors or readers, either as corrections of wrong data or as new documents.

Any substantial contribution (e.g. a document or an abstract) will always be explicitly acknowledged in BITRA with the name of the contributing person or institution. To make contribution easier, the website provides a "contribution form", which can also be accessed from the bottom of the searching page simply by clicking on "Comments or suggestions". In this form there is a window for each of the fields and, once the user has filled it in, it can be sent by simply clicking on "Send". The contribution then goes via e-mail and, if valid, will be included in the following month's update including a text which explicitly acknowledges the source. For a new document to be valid, it must contain at least the minimum data: author, year, title, place, publisher, pages, language and type.

\section{Structure and possibilities}

A detailed summary of the searching instructions an be found on the website. These are very user-friendly, but if you want to make the most of the database, it is advisable to read them. At the same time as I explain how it works, here I will mainly focus on its rationale and its possibilities.

BITRA is structured along the lines of a traditional database and is divided into 13 fields which allow the information to be compartmented so that searching can be as flexible and discriminating as possible. A complete document covers the following fields:

\section{SUBJECT:}

2. AUTHOR:

3. YEAR:

4. TITLE:

5. PLACE:

6. PUBLISHER:

7. PAGES:

8. LANGUAGE:

9. TYPE: 
10. UNIV. ALICANTE:

11. CONTENTS:

12. ABSTRACT:

13. COMMENTS:

In keeping with the idea of flexibility, it is possible to search in all of them simultaneously, individually or combining any number of fields. The searching page looks more or less like this:

DEPARTAMENT OF

ENGLISH STUDIES

BITRA.

BIBLIOGRAPHY OF INTERPRETING AND TRANSLATION OF ALICANTE

Categories for your search

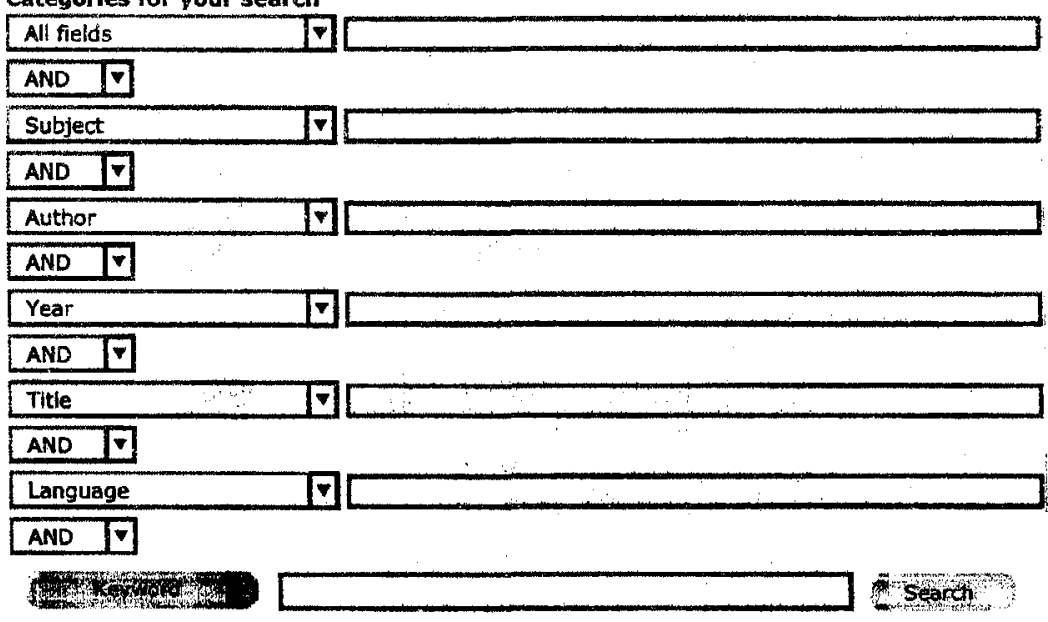

Select the fields you want to search and press SEARCH
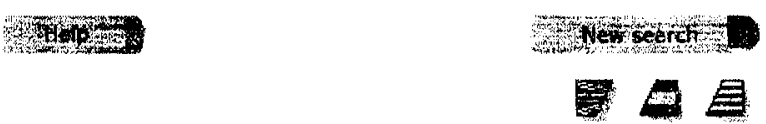

Copyright 2001 University of Alicante

comments or suggestions 
There is no need to use wildcards. If you introduce the string $<$ sar $>$ in the field "Author", you will get "Sara, Sarah, Cesarotti, Saramago, Sarcevic", etc. The search is not sensitive to upper or lower case, or to written accents, so it does not matter whether you write "INTERPRETING" or "interpreting "; García Márquez" or "garcia marquez".

The labels of all the windows can be changed to show any field, so that searching can be made-to-order and with any (combination of) field(s) as criteria. The first possibility shown is "All fields". This allows users to search for any string anywhere in the database. Of course, this involves a huge increase in the chances of finding information, wherever it may lie, but at the same time it also increases the chances of obtaining irrelevant data, an effect which cannot be disregarded given the already considerable size of the database. Instead, users are encouraged to refine their searches through concrete fields. Moreover, search strings can be combined through the logical operators .AND, .OR and .NOT, so that the chances of obtaining very accurate results are enhanced.

The results appear with all documents complete, in batches of five documents per window. Blank fields are automatically excluded. They are ordered by author and, for the same author, by year. To have the documents at their disposal, users only need to click on "Print".

Apart from the keywords, in the "Subject" field users can also gain access to the names of authors, works and countries (or other geographical areas, from continents to towns) whenever they are the subject of any document. Of course, a list of the thousands of possibilities involved would be impossible. As to the names of authors and works, they are always displayed in the way they are written in their original language, but if this does not use the Latin alphabet, their denomination in English and Spanish is offered instead (e.g. "Homero. Homer"). In the case of geographical terms, given the general ignorance as to the way they are called in their official language, the practice in BITRA is to use their English and Spanish names (e.g. "Polonia. Poland").

BITRA's list of keywords is provided on the next page.

I would like to finish this brief presentation describing some possible thematic searches so that their use and more or less specific potential can be clearly understood. The resulting numbers correspond to BITRA as at November, 2001.

Let us imagine that our main interest lies in technical translation. The first step would then be to click on "Keywords" and open the list. In the macrocategory GENRE we will see the keyword "Technical". We only need to click on it and on "Return" to place it in the appropriate window. If we then click on "Search", we will obtain the results (625 documents on technical translation) alphabetically ordered by author. Suppose, now, that we only want information on the translation of commercial texts. We simply select the keyword "commercial" from the keywords list and we will obtain 46 documents. If what we really want is to see what handbooks on commercial translations have been published, we only need to add the keyword "Handbook" (selected from the keywords list) to the keyword "Commercial". We will then be able to see five handbooks which deal with commercial translation and interpreting.

To take another example, let us imagine we are looking for texts on drama translation. In the macrocategory GENRE we will see the keyword "Drama". We only need to click on it and on "Return" to place it in the appropriate window. If we then click on "Search", we will obtain 
the resuits (334 documents on drama translation) alphabetically ordered by author. Suppose, now, that we only want information on the translation of Shakespeare's plays. We simply select the "Subject" option in any window and type in the word "Shakespeare". This reduces the list to 98 documents by excluding any texts on drama which do not refer to Shakespeare as well as any which deals only with his poetry. Let us further imagine we only want texts on the translation of Hamlet. Then we need only to type in a window with "Subject" the words "Hamlet" and "Shakespeare" (if we only write "Hamlet" we will also bring up texts on the homonymous work by Faulkner) and we will obtain 12 results which focus on the translation of Shakespeare's play. These texts are in several languages, but if you wish, you can also limit this to just one, English for instance, by adding the word "English" in a window with "Language" in it. The results will now be 4 texts written in English and dealing with the translation of Shakespeare's Hamiet.

BITRA - KEYWORDS

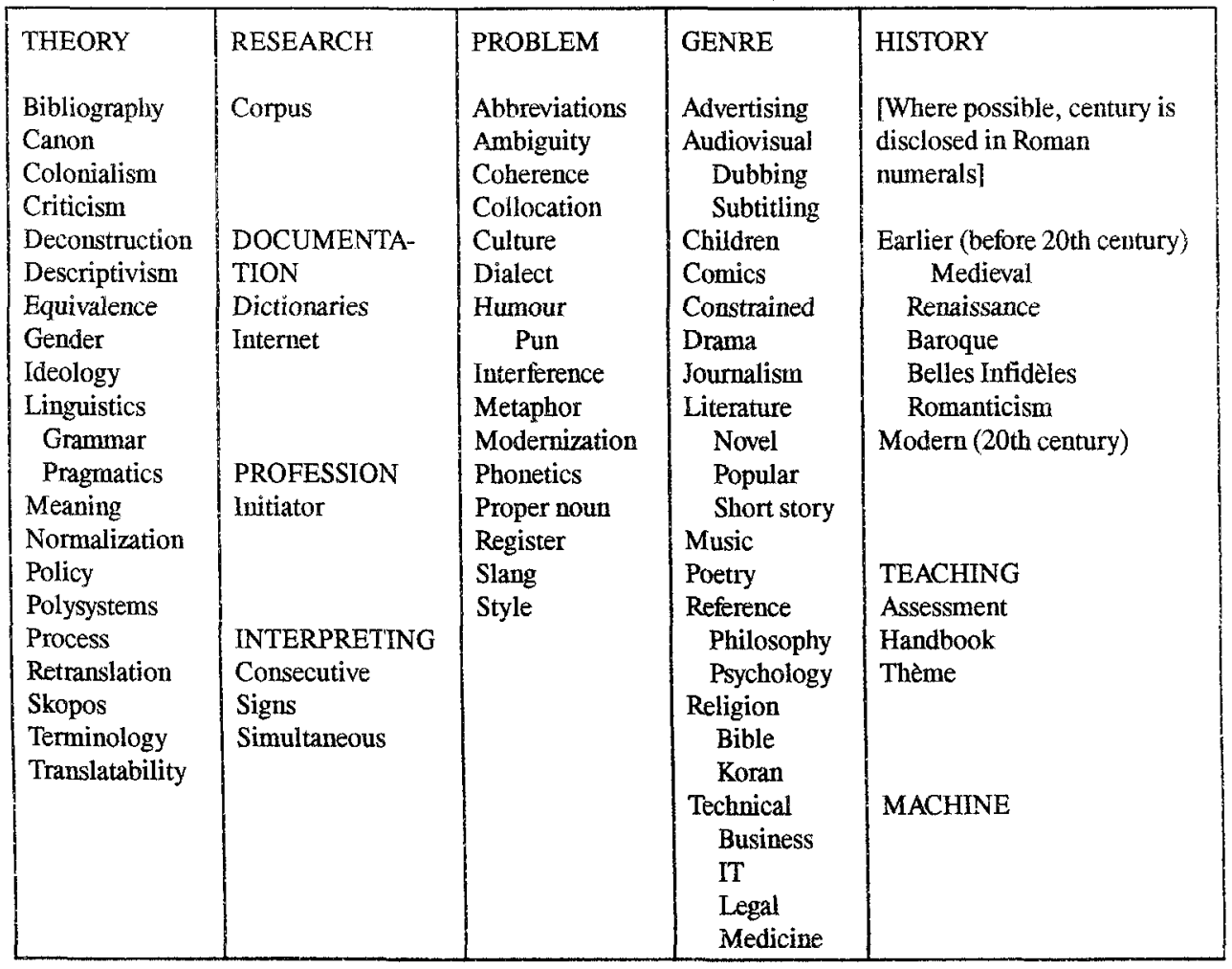


As a final illustration, let us imagine we are looking for texts on interpreting. If we open up the "Keywords" list, we will find the macrocategory "Interpreting". Clicking on it we will obtain 632 documents. Perhaps our interest lies in the teaching of interpreting. Then we only need to add the keyword "teaching" and we will obtain 296 documents on this combination of subjects. We can still be more specific and ask for texts on the assessment of interpreting. It will then be enough to select the keywords "interpreting" and "assessment" from the key words list. The result will be 37 documents on the evaluation of interpreting. We can also look for geographical issues, and search, for instance, for texts on the teaching of interpreting and/or translation in a given country. In that case, we only need to write the name of the country in a "Subject" window and select the keyword "Teaching". Thus, "Spain" and "Teaching" will produce 38 documents, whereas "China" and "Teaching" will produce 11 documents, etc.

To illustrate how the results are presented, here is a document as it appears in the English version of BITRA (see next page). It is a book published on CD-ROM, the first result of a search for "Interference" and "Medicine" (both keywords).

The possibitities for students, scholars and professionals of obtaining useful information from BITRA are almost boundless and will continue to increase as the database grows. At the moment and due to obvious reasons of accessibility, BITRA is probably still biased in favour of Spanish (c. 1,900) and English (c. 4,000) texts vs. other languages (in French, for instance, there are about 1,150). However, it must not be forgotten that English increasingly plays the role of lingua franca in scientific communication, including translation and interpreting, so it is very much to be expected that this language will always be dominant. If the academic and professional communities consider it worthwhile to contribute their own publications or those they know of, BITRA will soon be a very reliable guide to everything ever published in our (inter)discipline, with the result that the data will be more and more representative and complete.

Apart from the obvious possibilities we have discussed so far of gaining access to a complete and annotated bibliography on the author, publisher, journal, subject, language, year, etc. we might be interested in, BITRA can also provide some precious data on the nature and approach of the theoretical and applied branches of translation and interpreting throughout history. Here are just a few of the issues which BITRA might help users address:

* The relative preponderance of the different languages.

* What subjects and which approaches have been most commonly addressed in the past and now. For instance:

* How and when the different schools of Translation Studies appeared.

* When theoretical (vs. applied) considerations find their way into interpreting or into technical texts.

* The status of translators in the past and the present.

* When and how machine translation came into documentation. When and how the idea of machine translation evolved.

* The types of text most frequently dealt with. Is the translation of canonical texts still almost the only issue addressed? 


\section{BITRA. \\ BIBLIOGRAPHY OF INTERPRETING AND TRANSLATION OF ALICANTE}

Results: 10 Result(s)

Subject: Medicine. Dictionaries. Documentation. Interference. Terminology. Linguistics. Abbreviations, Genre. Technical. Theory: Problem

Author: Alcaraz Ariza, Maria Angeles:

Year: 2000

Title: Anglicismo en el lenguaje de las ciencias de la salud [Anglicisms in the language of health sciences]

Place: Alicante

Publisher: Univ. Alicante

Pages: 1-696

Language: Español. Spanish.

Type: Electrónico. Electronic. Libro. Book. CO-ROM.

Contents: Introducción. Capítulo 1: Lenguas especiales Capitulo 2: Comunicación especializada. Caṕpitulo 3: Lenguaje médico. Capítulo 4: Préstamos Capítulo 5: Formaciones. sigladas. Caṕtulo 6: Anglicismos léxicos (I). Capitulo 7: Anglicismos léxicos (11). Capítulo 8: Anglicismos léxicos (III). Capítulo 9: Anglicismos semánticos. Capítulo 10: Anglicismos sintácticos. Capitulo 11: Aspectos lexicográficos. Capítulo 12: El uso de los anglicismos en el ámbito médico: análisis empírico (1). Capítulo 13: Aspectos fonológicos: análisis empírico (ii). Conclusiones y reflexiones finales. Giosario. Bibliografia.

Ahstract: This study is a descriptive and sociolinguistic approach to the influence of English on the Spanish used in the domain of health sciences. It is divided into three parts, the first one bearing on theory and the other two being practical in conception. The first part deals with several points: acquisition process, functions, and reasons for the development of specialized languages, tinguistic and extralinguistic criteria of English borrowings in medical Spanish, and conceptual and linguistic development of medical science. The second part tackles different kinds of anglicisims callected from written and oral sources (specialized journals, medical dictionaries, and interviews. with people involved in the health sclences). The third part is concerned with lexicographical and statistical aspects: linguists' and published physicians' opinions about the English influence on Spanish, study of general and medical dictionaries in different languages, and analysis of oral anglicisms used by the medical community. The study also includes a glossary of quotations comiaining the anglicisms analyzed and a supporting bibliography. [Source: Author]

Comments: ISBN: 84-7908-555-X. 
In its few months of existence, some friends and colleagues have commented that the effort of updating and improving BITRA might be excessive. The truth is that the project is fascinating and that, for the moment, the effort is more than rewarding. Furthermore, BITRA has already the selfless support of several members of staff at the University of Alicante and other institutions. If the academic and professional communities consider it a helpful tool and start to contribute to a database which aspires to belong to everybody and be made up from acknowledged contributions from everybody, the potential as I said above, is almost infinite.

Currently, I have two projects which I plan to launch when BITRA has become consolidated as a significant and reasonably complete representation of all the literature on translation and interpreting. The first of these would be to add a "Reviews" field to complete the metatextual information already supplied. This section would not be restricted to mentioning reviews already published in the different journals but would add those sent by BITRA users, linking them directly to the documents themselves. Of course, these reviews would always have to go through an academic filter to guarantee their quality. Thus, the documents would have readily available links with critical and favourable comments which could give a very complete idea of the different possible readings and implications of a given text.

The second project is to issue an electronic publication focusing specifically on the study of the bibliography of translation and interpreting. It would deal with research into the state of the art and into the historical background of any issue, in line with the possible issues BITRA enables us to address. Linking this publication with BITRA would make it much easier to locate and would enable readers to look through the relevant annotated bibliography by themselves.

I hope that BITRA will meet with the approval of all those concerned with translation and interpreting. It only remains to add that I personally would welcome any suggestions for the improvement of this database.

$* * * * * * * *$

Acknowledgements: BITRA has the support of the Spanish Ministerio de Educación y Cultura through research project PB98-1062-C04-04. 